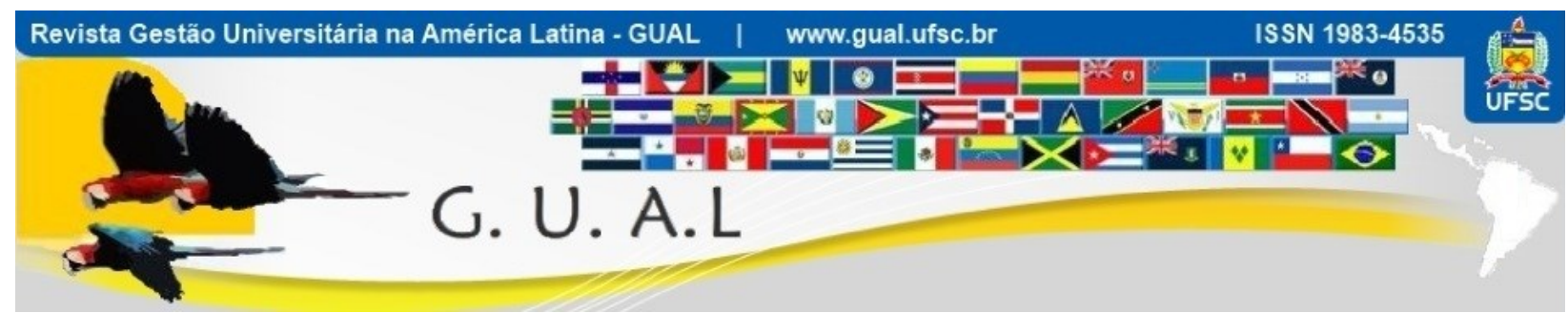

DOI: http://dx.doi.org/10.5007/1983-4535.2014v7n1p191

\title{
AVALIAÇÃO DE CURSOS DE GRADUAÇÃO NA MODALIDADE A DISTÂNCIA: UMA EXPERIÊNCIA NO CURSO DE GRADUAÇÃO EM ADMINISTRAÇÃO DA UNIVERSIDADE FEDERAL DE SANTA CATARINA
}

\section{EVALUATION OF DISTANCE LEARNING UNDERGRADUATE COURSES: AN EXPERIENCE FROM FEDERAL UNIVERSITY OF SANTA CATARINA'S BUSINESS MANAGEMENT COURSE}

Cláudia Medianeira Cruz Rodrigues, Doutora Universidade Federal do Rio Grande do Sul - UFRGS claudia.rodrigues@producao.ufrgs.br

Rogério da Silva Nunes, Doutor Universidade Federal de Santa Catarina - UFSC rognunes@msn.com

Gilberto Müller Beuren, Mestre Universidade Federal do Rio Grande do Sul - UFRGS gilberto.beuren@sai.ufrgs.br

Bernardo Sfredo Miorando, Mestrando Universidade Federal do Rio Grande do Sul - UFRGS bernardosfredo@ufrgs.br

Recebido em 23/junho/2013

Aprovado em 29/novembro/2013

Sistema de Avaliação: Double Blind Review

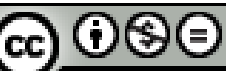

Esta obra está sob uma Licença Creative Commons Atribuição-Uso. 


\title{
AVALIAÇÃO DE CURSOS DE GRADUAÇÃO NA MODALIDADE A DISTÂNCIA: UMA EXPERIÊNCIA \\ NO CURSO DE GRADUAÇÃO EM ADMINISTRAÇÃO DA UNIVERSIDADE FEDERAL DE SANTA CATARINA \\ DOI: http://dx.doi.org/10.5007/1983-4535.2014v7n1p191
}

\section{RESUMO}

O artigo apresenta uma proposta de instrumento de avaliação de Cursos de Graduação na modalidade a distância. Em processo de validação, foi realizada uma aplicação no Curso de Graduação em Administração, modalidade a distância, em dez polos localizados no Estado de Santa Catarina: Araranguá, Canoinhas, Chapecó, Criciúma, Florianópolis, Joinville, Lages, Laguna, Palhoça e Tubarão. O instrumento é dividido nas dimensões corpo docente, organização didático-pedagógica e instalações físicas, tal qual está previsto no Sistema Nacional de Avaliação da Educação Superior (SINAES). Estão apresentados os resultados por polo e há um tratamento quantitativo dos 157 instrumentos respondidos pelos estudantes com relação aos constructos Os resultados permitiram identificar a satisfação dos estudantes, onde os melhores índices de aprovação em cada constructo foram: professores, no polo de Joinville; tutores presenciais, Joinville; tutores a distância, Laguna; coordenação de curso e de polo, Laguna; sistema de ensino, Joinville; participação em atividades acadêmicas, Joinville; organização do curso, Canoinhas; expectativas referentes à conhecimento e empregabilidade, Joinville; condições do polo, Chapecó; suporte acadêmico/técnico, Canoinhas; e tecnologias da informação (TIC's), no polo de Joinville.

Palavras-chave: Avaliação. Educação a distância. Administração. SINAES.

\begin{abstract}
The paper presents an instrument for assessing undergraduate courses in distance mode. In the validation process, an application was made in an undergraduation course on Business Management, in distance education mode, in ten centers from Santa Catarina State: Araranguá, Canoinhas, Chapecó, Criciúma, Florianópolis, Joinville, Lages, Laguna, Palhoça and Tubarão. The instrument comprises the dimensions of teaching staff, didactic-pedagogic organization and infrastructure, it is foreseen in the Brazilian National System of Higher Education Evaluation (SINAES). The results are presented by center and there is a quantitative treatment of the 157 instruments answered by the students, consolidating the answers in constructs for the areas which compose the three dimensions. The results allowed the identification of students' satisfaction. The best indexes for each construct were: teachers, in the Joinville center; face-to-face tutors, Joinville; distance tutors, Laguna; course and center coordination, Laguna; teaching system, Joinville; participation in academic activities, Joinville; course structure, Canoinhas; expectations on knowledge and employability, Joinville; center conditions, Chapecó; academic/technical support, Canoinhas; and information and communication technologies (ICTs), Joinville.
\end{abstract}

Keywords: Evaluation. Distance learning. Business Management. SINAES. 


\section{AVALIAÇÃO DE CURSOS DE GRADUAÇÃO NA MODALIDADE A DISTÂNCIA: UMA EXPERIÊNCIA \\ NO CURSO DE GRADUAÇÃO EM ADMINISTRAÇÃO DA UNIVERSIDADE FEDERAL DE SANTA \\ DOI: http://dx.doi.org/10.5007/1983-4535.2014v7n1p191}

\section{INTRODUÇÃO}

Os dados das Sinopses Estatísticas da Educação Superior, produzidas pelo Instituto Nacional de Estudos e Pesquisas Educacionais Anísio Teixeira (INEP), dão conta do crescimento da graduação na modalidade à distância (EAD). Em 2001, havia no Brasil 3.030.754 matrículas em cursos de graduação presencial, enquanto se registravam apenas 5.359 na modalidade a distância (0,18\% das matrículas). Dez anos após, em 2011, estes números ampliaram para 5.746.762 matrículas no presencial, enquanto a EAD passou para 992.927 matrículas (17,28\% das matrículas). (INEP, 2013)

Percebe-se, assim, uma contribuição da EAD para a consecução da meta de expansão da cobertura de educação superior e a necessidade de consolidar um instrumento de avaliação em tal modalidade, para assegurar uma ampliação com qualidade. A regulamentação dos processos de avaliação dos cursos de graduação existe, mas ainda é recente com relação à EAD e, portanto, há espaço para iniciativas que busquem contribuir em tal consolidação de instrumentos de avaliação.

$\mathrm{O}$ artigo pretende contribuir em tal esforço ao elaborar um instrumento de avaliação de cursos de graduação em EAD (RODRIGUES ET AL., 2013, no prelo), já utilizado para verificar a opinião de estudantes de uma licenciatura e um curso superior de tecnologia na Universidade Federal do Rio Grande do Sul (UFRGS) em tal modalidade (RODRIGUES; MIORANDO, 2012) e aqui testado em um bacharelado.

O curso em questão é o Projeto Piloto, acesso universal, de Graduação em Administração da Universidade Federal de Santa Catarina, resultado de um convênio institucional com o Ministério da Educação e com o Banco do Brasil, que teve o primeiro ingresso em 2006, dedicado a servidores públicos e do Banco do Brasil em dez municípios de Santa Catarina: Araranguá, Canoinhas, Chapecó, Criciúma, Florianópolis, Joinville, Lages, Laguna, Palhoça e Tubarão. Em 2008, houve o segundo ingresso, com a oferta de 400 vagas em processo seletivo com acesso a todos interessados nos polos de apoio presencial das comunidades.

A aplicação do instrumento ocorreu nos ingressantes do acesso universal em agosto de 2011. Na ocasião, havia 347 estudantes ativos no controle acadêmico da Universidade Federal de Santa Catarina, a quem foram encaminhados os instrumentos de pesquisa, e foram obtidos 157 questionários respondidos, um índice superior a 45\% de respondentes. 


\section{AVALIAÇÃO DE CURSOS DE GRADUAÇÃO NA MODALIDADE A DISTÂNCIA: UMA EXPERIÊNCIA \\ NO CURSO DE GRADUAÇÃO EM ADMINISTRAÇÃO DA UNIVERSIDADE FEDERAL DE SANTA \\ DOI: http://dx.doi.org/10.5007/1983-4535.2014v7n1p191}

Por fim cabe destacar que havia 81 cursos de Administração na modalidade EAD no Brasil, curso com maior oferta entre os bacharelados e o segundo, considerando todos os tipos de graduação. Essa posição se mantém quando se toma o número de matrículas, com 140.210 (INEP, 2013). Espera-se, portanto, que o artigo contribua para uma discussão da avaliação da virtualização da educação superior no Brasil.

\section{REFERENCIAL TEÓRICO}

Nos últimos anos, a ação do governo brasileiro tem se guiado pela meta de expandir a oferta de educação superior. O Plano Nacional de Educação (PNE), previsto para vigorar de 2001 a 2010, trazia como meta a provisão do ensino superior a 30\% da população entre 18 e 24 anos, atingindo um nível inédito de massificação (BRASIL, 2001). Tal meta não foi atingida, a Pesquisa Nacional por Amostra de Domicílios (PNAD) de 2011 situou em 14,6\% a taxa de frequência líquida a cursos de graduação por este grupo populacional (IBGE, 2012). Assim, o PNE para o decênio 2011-2020, traz como meta a elevação para 33\%, assegurada a qualidade da oferta (BRASIL, 2010).

Para obter tais resultados, os governos brasileiros têm adotado políticas conducentes à construção de um moderno mercado de educação superior no Brasil. O posicionamento estatal é condizente com as tendências da globalização, favorecendo uma liberalização do setor, com ampliação da participação de instituições privadas e aumento da competição. Entre os resultantes da busca pela competitividade, está a difusão da oferta de cursos superiores sob formatos variados (GOMES; ROBERTSON; DALE, 2012). Verifica-se, então, uma diferenciação rumo à diversidade:

\footnotetext{
Em busca de uma sintética definição destes termos, encontra-se usualmente diversidade como um critério pelo qual se pode descrever, comparar, classificar e avaliar sistemas, instituições, programas e funções da Educação Superior, em qualquer ponto no tempo e no espaço. Refere-se, por conseguinte, a um estado ou qualidade relativa de um todo e suas partes. Correlatamente, diferenciação designa um processo pelo qual se examina ou interpreta a dinâmica de mudança, pela qual um sistema ou instituição é levado a determinado estado de diversidade. Por isso, pode-se encontrá-la também como uma estratégia no planejamento institucional e na reforma educacional (LUCE, 2001, p. 3, grifos no original).
}

Esta aí abarcada a diferenciação programática e curricular que envolve novas formas de cursos na educação superior brasileira, que se intensifica na última década. $O$ fenômeno responde a uma maior demanda por qualificação, principalmente, por parte de pessoas distantes dos grandes centros urbanos, onde se situam as universidades, e os que necessitam 


\title{
AVALIAÇÃO DE CURSOS DE GRADUAÇÃO NA MODALIDADE A DISTÂNCIA: UMA EXPERIÊNCIA \\ NO CURSO DE GRADUAÇÃO EM ADMINISTRAÇÃO DA UNIVERSIDADE FEDERAL DE SANTA CATARINA \\ DOI: http://dx.doi.org/10.5007/1983-4535.2014v7n1p191
}

de horários flexíveis para realizar seus estudos. Para proporcionar esta possibilidade e incluir um contingente que não teve como ser atendido com o incremento da oferta de cursos noturnos, a modalidade à distância (EAD) inclui uma utilização maior de recursos tecnológicos, em especial os de telecomunicações e tecnologia da informação, constituindo-se e se fortalecendo a partir das experiências de virtualização da universidade. Pode-se dizer que:

Em termos gerais, a virtualização é, ao mesmo tempo, um processo e resultado do tratamento e da comunicação de dados, informações e conhecimentos mediante computadores. Mais especificamente, a virtualização consiste em representar eletronicamente e de forma numérica digital objetos e processos que encontramos no mundo real. No contexto da educação superior, a virtualização pode envolver a representação de processos e objetos associados a atividades de ensino e aprendizagem, de pesquisa e gestão, assim como objetos cuja manipulação permite ao usuário realizar diversas operações através da internet, tais como aprender mediante a interação com cursos eletrônicos, inscrever-se em um curso, consultar documentos em uma biblioteca eletrônica, comunicar-se com estudantes e professores, e outros (SILVIO, 1998, p. 28, tradução livre).

Por um lado, estes fenômenos respondem inicialmente a um ambiente de competitividade econômica, utilizados como estratégia por instituições privadas, e seu sucesso sinaliza aos agentes públicos a necessidade de investimento nestes processos, de modo a incluir aqueles que não podem acessá-la nas formas tradicionais. Tem-se, então, que a educação a distância (EAD) vem se mostrando uma modalidade promissora, com tendência entre os países latino-americanos de investimento em tal modalidade, onde o Brasil não é exceção, mas expoente:

\begin{abstract}
A expansão da educação a distância na região está se expressando em novas modalidades institucionais públicas e em novas articulações pedagógicas dos processos de aprendizagem no marco da busca de aumentar a cobertura e reduzir a inequidade de acesso. Os casos mais significativos de fortes políticas públicas de promoção da EAD se expressaram na criação da Universidade Aberta do Brasil, nos Centros Regionais de Educação Superior na Colômbia e na municipalização da educação superior em Cuba. Expressam modalidades diferenciadas de aumento da cobertura, de ação pública e de articulações entre o Estado e a academia. São a expressão dos anos 2000 da vontade dos governos de aumentar as oportunidades de estudo em contextos de dificuldades de promoção das mesmas modalidades de acesso presenciais (RAMA, 2008, p. 348, tradução livre).
\end{abstract}

A garantia da qualidade dos cursos de graduação é feita no Brasil a partir de regulação por parte do Estado que deve (1) autorizar seu funcionamento, (2) reconhecê-los oficialmente e (3) renovar seu reconhecimento. Tais processos são definidos no âmbito do Sistema Nacional de Avaliação da Educação Superior (SINAES). A dinamicidade do campo da educação superior se reflete em mudanças nos dispositivos da avaliação, que precisam aprofundar o diálogo com a diversidade. Assim, se os formulários de avaliação externa do 


\title{
AVALIAÇÃO DE CURSOS DE GRADUAÇÃO NA MODALIDADE A DISTÂNCIA: UMA EXPERIÊNCIA \\ NO CURSO DE GRADUAÇÃO EM ADMINISTRAÇÃO DA UNIVERSIDADE FEDERAL DE SANTA CATARINA \\ DOI: http://dx.doi.org/10.5007/1983-4535.2014v7n1p191
}

SINAES trazem critérios de verificação da qualidade dos cursos EAD, as universidades também não podem se furtar a essa verificação. Ao fazê-lo, precisam estar cientes das transformações nos modelos de ensino e de elementos de qualidade nem sempre avaliados em nível sistêmico.

\begin{abstract}
A massificação, a expansão institucional e a complexidade de níveis e modalidades, assim como a própria reflexão dos critérios, procedimentos e a organização das instituições de avaliação e acreditação evocam a necessidade de formular novos critérios de avaliação. Em sua ocasião, eles foram definidos no calor das tensões e da resolução política das diferenças geradas na etapa de discussão da criação das agências de avaliação na década de noventa, sobre seu caráter voluntário, as concepções de qualidade que vogavam neste momento, as resistências à avaliação externa, a ausência de padrões mínimos, a predominância de enfoques nacionais academicistas e a escala e dimensão dos problemas de então em um contexto de poucas instituições, programas e estudantes. Tais paradigmas se davam em modelos presencias e de elites que hoje já não existem; portanto, não apenas estamos ante sistemas de massas, mas a educação a distância é cada vez mais significativa numericamente (RAMA, 2012, p. 215-216, tradução livre).
\end{abstract}

Ganhando significância e sendo palco de práticas e paradigmas emergentes, a EAD demanda formas de avaliação novas e condizentes com as particularidades de suas realidades. Assim, são postas em questão não apenas as práticas do sistema de educação superior, mas também as de cada instituição. De fato, a própria Lei do SINAES valoriza a autoavaliação e a incorpora em suas dimensões (BRASIL, 2004).

Conduzir a autoavaliação de seus cursos EAD, verificando sua qualidade e buscando sua melhoria é, portanto, uma responsabilidade da universidade no contexto da virtualização. Este contexto abarca elementos e dimensões que não são características do ensino presencial. Faller (2009) ressalta os seguintes grupos de peculiaridades da EAD: (i) as tecnologias; (ii) a estrutura dos polos, assim como o Projeto Pedagógico do Curso (PPC); (iii) as pessoas que oportunizam que o PPC seja colocado em prática, conforme apresentado na Figura 1.

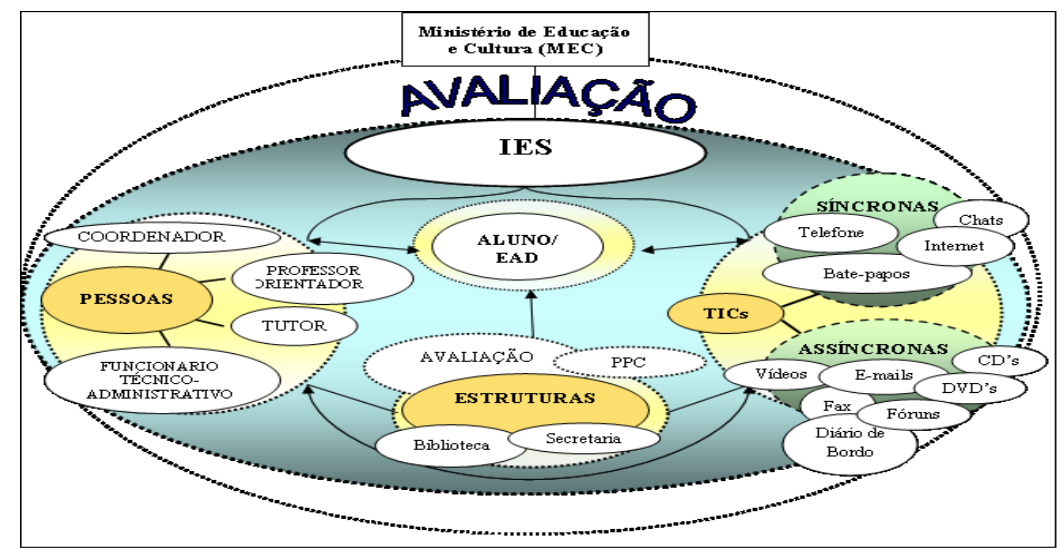

Figura 1 Ambiente da educação a distância. Fonte: Faller (2009). 


\section{AVALIAÇÃO DE CURSOS DE GRADUAÇÃO NA MODALIDADE A DISTÂNCIA: UMA EXPERIÊNCIA \\ NO CURSO DE GRADUAÇÃO EM ADMINISTRAÇÃO DA UNIVERSIDADE FEDERAL DE SANTA \\ DOI: http://dx.doi.org/10.5007/1983-4535.2014v7n1p191}

\section{PROCEDIMENTOS METODOLÓGICOS}

O estudo é caracterizado como estudo de caso que, na concepção de Yin (2007, p. 32), "é uma investigação empírica que investiga um fenômeno contemporâneo dentro de seu contexto da vida real, especialmente quando os limites entre o fenômeno e o contexto não estão claramente definidos". O estudo de caso foi realizado na Universidade Federal de Santa Catarina e teve como objeto de pesquisa o Curso de Graduação em Administração na educação a distância.

A coleta de dados foi efetuada em três etapas. Inicialmente, foi realizada pesquisa bibliográfica, a partir dos instrumentos e da legislação relacionada à educação a distância disponibilizada pelo Ministério da Educação, assim como da literatura disponível sobre o tema. Esta etapa permitiu a construção da versão preliminar do instrumento de avaliação. $\mathrm{Na}$ segunda, foi realizada uma pesquisa de campo para aplicação de um pré-teste do instrumento de avaliação junto aos alunos do Curso de Administração a distância da UFSC, modalidade bacharelado, ofertado em dez polos no Estado de Santa Catarina: Araranguá, Canoinhas, Chapecó, Criciúma, Florianópolis, Joinville, Lages, Laguna, Palhoça e Tubarão. A terceira etapa consistiu na consolidação do instrumento através de sua validação junto à amostra considerada (Apêndice A).

A escala adotada no instrumento de coleta é de concordância, onde 1 refere-se a Discordo Plenamente e 5 a Concordo Plenamente. O instrumento possui 67 itens que avaliam o grau de concordância geral do aluno em relação às seguintes dimensões e constructos:

(1) Corpo docente, corpo de tutores e coordenação: compreende Professores, Tutores Presenciais, Tutores a Distância e Coordenação de Curso e Polo;

(2) Organização didático-pedagógica: compreende Sistema de Ensino, Participação em Atividades Acadêmicas, Organização do Curso e Expectativas referentes à Conhecimento e Empregabilidade;

(3) Instalações físicas: compreende Condições do Polo, Suporte Acadêmico/Técnico e Tecnologias de Informação e Comunicação (TIC). 


\section{AVALIAÇÃO DE CURSOS DE GRADUAÇÃO NA MODALIDADE A DISTÂNCIA: UMA EXPERIÊNCIA \\ NO CURSO DE GRADUAÇÃO EM ADMINISTRAÇÃO DA UNIVERSIDADE FEDERAL DE SANTA \\ DOI: http://dx.doi.org/10.5007/1983-4535.2014v7n1p191}

\section{RESULTADOS}

O instrumento foi aplicado em agosto de 2011 e os resultados analisados nos meses de outubro a dezembro do mesmo ano. Houve 157 estudantes respondentes ao instrumento, que foi inserido e disponibilizado através da plataforma de aprendizagem utilizada pelo Curso.

\subsection{DESCRIÇÃO DA AMOSTRA}

A população é formada pelos estudantes matriculados no Curso de Administração, modalidade EAD da UFSC, distribuída entre os polos de (1) Araranguá, (2) Canoinhas, (3) Chapecó, (4) Criciúma, (5) Florianópolis, (6) Joinville, (7) Lages, (8) Laguna, (9) Palhoça e Tubarão (10).

O instrumento de pesquisa foi encaminhado aos 347 estudantes com matrícula regular no curso, dos quais 157 responderam à pesquisa, com retorno de 45,24\% e respondentes em todos os polos onde o curso é oferecido.

\subsection{PERFIL DOS ENTREVISTADOS}

A primeira parte do instrumento buscou caracterizar os respondentes. Basicamente, são do sexo masculino $(53,50 \%)$, não tem filhos $(49,04 \%)$, casado $(52,87 \%)$, trabalham como funcionário do governo federal, estadual ou municipal $(38,85 \%)$ e possuem renda familiar entre 4 e 10 Salários Mínimos (51,61\%). A tabela 1 apresenta a descrição do perfil:

Tabela 1 Descrição geral da amostra, distribuição \% das diferentes categorias

\begin{tabular}{|c|c|c|c|c|c|c|c|c|c|c|c|}
\hline Variáveis & $\begin{array}{l}\text { Polo } \\
1\end{array}$ & $\begin{array}{l}\text { Polo } \\
2\end{array}$ & $\begin{array}{l}\text { Polo } \\
3 \\
\end{array}$ & $\begin{array}{c}\text { Polo } \\
4\end{array}$ & $\begin{array}{l}\text { Polo } \\
5\end{array}$ & $\begin{array}{l}\text { Polo } \\
6\end{array}$ & $\begin{array}{l}\text { Polo } \\
7\end{array}$ & $\begin{array}{l}\text { Polo } \\
8\end{array}$ & $\begin{array}{l}\text { Polo } \\
9\end{array}$ & $\begin{array}{l}\text { Polo } \\
10\end{array}$ & $\begin{array}{l}\% \\
\text { Total }\end{array}$ \\
\hline $\begin{array}{l}\text { Sexo } \\
\text { Feminino } \\
\text { Masculino }\end{array}$ & $\begin{array}{l}34,78 \\
65,22\end{array}$ & $\begin{array}{l}26,27 \\
73,33\end{array}$ & $\begin{array}{l}52,63 \\
47,37\end{array}$ & $\begin{array}{l}40,00 \\
60,00\end{array}$ & $\begin{array}{l}40,00 \\
60,00\end{array}$ & $\begin{array}{l}64,29 \\
35,71\end{array}$ & $\begin{array}{l}30,77 \\
69,23\end{array}$ & $\begin{array}{l}76,92 \\
23,08\end{array}$ & $\begin{array}{l}47,37 \\
52,63\end{array}$ & $\begin{array}{l}63,64 \\
36,36\end{array}$ & $\begin{array}{l}46,50 \\
53,50\end{array}$ \\
\hline $\begin{array}{l}\text { Número de filhos } \\
\text { Nenhum } \\
\text { Um } \\
\text { Dois } \\
\text { Três } \\
\text { Quatro ou mais }\end{array}$ & $\begin{array}{l}26,09 \\
39,13 \\
30,43 \\
4,35 \\
0,00\end{array}$ & $\begin{array}{l}46,67 \\
13,33 \\
26,67 \\
13,33 \\
0,00\end{array}$ & $\begin{array}{l}68,42 \\
21,05 \\
10,53 \\
0,00 \\
0,00\end{array}$ & $\begin{array}{l}45,00 \\
30,00 \\
20,00 \\
5,00 \\
0,00\end{array}$ & $\begin{array}{l}40,00 \\
40,00 \\
10,00 \\
0,00 \\
10,00\end{array}$ & $\begin{array}{l}64,29 \\
21,43 \\
7,14 \\
0,00 \\
7,14\end{array}$ & $\begin{array}{l}53,85 \\
23,08 \\
7,69 \\
15,38 \\
0,00\end{array}$ & $\begin{array}{l}46,15 \\
23,08 \\
7,69 \\
0,00 \\
23,08\end{array}$ & $\begin{array}{l}52,63 \\
21,05 \\
15,79 \\
0,00 \\
10,53\end{array}$ & $\begin{array}{l}54,55 \\
18,18 \\
18,18 \\
9,09 \\
0,00\end{array}$ & $\begin{array}{l}49,04 \\
25,48 \\
16,56 \\
4,46 \\
4,46\end{array}$ \\
\hline $\begin{array}{l}\text { Estado Civil } \\
\text { Casado } \\
\text { Solteiro } \\
\text { Separado } \\
\text { Viúvo } \\
\text { Outro } \\
\end{array}$ & $\begin{array}{l}60,87 \\
26,09 \\
8,69 \\
4,35 \\
0,00\end{array}$ & $\begin{array}{l}53,33 \\
33,33 \\
6,67 \\
0,00 \\
6,67\end{array}$ & $\begin{array}{l}42,10 \\
5,26 \\
42,10 \\
0,00 \\
10,53\end{array}$ & $\begin{array}{l}55,00 \\
30,00 \\
5,00 \\
0,00 \\
10,00\end{array}$ & $\begin{array}{l}50,00 \\
30,00 \\
0,00 \\
0,00 \\
20,00\end{array}$ & $\begin{array}{l}64,29 \\
35,71 \\
0,00 \\
0,00 \\
0,00\end{array}$ & $\begin{array}{l}53,85 \\
38,46 \\
0,00 \\
0,00 \\
7,69\end{array}$ & $\begin{array}{l}38,46 \\
46,15 \\
15,38 \\
0,00 \\
0,00\end{array}$ & $\begin{array}{l}52,63 \\
42,11 \\
5,26 \\
0,00 \\
0,00\end{array}$ & $\begin{array}{l}54,55 \\
36,36 \\
9,09 \\
0,00 \\
0,00\end{array}$ & $\begin{array}{l}52,87 \\
35,67 \\
5,73 \\
0,64 \\
5,09\end{array}$ \\
\hline $\begin{array}{l}\text { Ocupação } \\
\text { Comércio, banco, } \\
\text { transporte, hotelaria ou }\end{array}$ & 60,87 & 33,33 & 26,32 & 30,00 & 30,00 & 7,14 & 7,69 & 30,77 & 26,32 & 45,45 & 31,21 \\
\hline
\end{tabular}




\section{AVALIAÇÃO DE CURSOS DE GRADUAÇÃO NA MODALIDADE A DISTÂNCIA: UMA EXPERIÊNCIA NO CURSO DE GRADUAÇÃO EM ADMINISTRAÇÃO DA UNIVERSIDADE FEDERAL DE SANTA CATARINA \\ DOI: http://dx.doi.org/10.5007/1983-4535.2014v7n1p191}

\begin{tabular}{|c|c|c|c|c|c|c|c|c|c|c|c|}
\hline $\begin{array}{l}\text { Funcionário(a) do } \\
\text { governo federal, } \\
\text { estadual ou municipal }\end{array}$ & 21,74 & 26,67 & 47,37 & 35,00 & 50,00 & 50,00 & 53,85 & 38,46 & 52,63 & 18,18 & 38,85 \\
\hline $\begin{array}{l}\text { Profissional liberal, } \\
\text { professor ou técnico de } \\
\text { nível superior }\end{array}$ & 0,00 & 6,67 & 0,00 & 20,00 & 0,00 & 0,00 & 0,00 & 7,69 & 10,53 & 9,09 & 5,73 \\
\hline $\mathrm{Na}$ indústria & 8,69 & 26,67 & 15,79 & 15,00 & 0,00 & 14,29 & 15,38 & 0,00 & 5,26 & 9,09 & 11,47 \\
\hline Na construção civil & 0,00 & 6,67 & 0,00 & 0,00 & 10,00 & 7,14 & 15,38 & 15,38 & 0,00 & 9,09 & 5,10 \\
\hline Não trabalha & 4,35 & 0,00 & 5,26 & 0,00 & 10,00 & 7,14 & 7,69 & 7,69 & 0,00 & 0,00 & 3,82 \\
\hline Outro & 4,35 & 0,00 & 5,26 & 0,00 & 0,00 & 14,29 & 0,00 & 0,00 & 5,26 & 9,09 & 3,82 \\
\hline Renda & & & & & & & & & & & \\
\hline $\begin{array}{l}\mathrm{R} \$ 0 \text { a } \mathrm{R} \$ 1020,00 \text { (até } 2 \\
\text { S.M.) }\end{array}$ & 0,00 & 0,00 & 0,00 & 0,00 & 0,00 & 0,00 & 0,00 & 23,08 & 0,00 & 0,00 & 1,94 \\
\hline $\begin{array}{l}\mathrm{R} \$ 1020,00 \text { a } \\
2040,00\end{array}$ & 30,43 & 26,67 & 15,79 & 10,00 & 10,00 & 30,77 & 15,38 & 15,38 & 11,11 & 18,18 & 18,71 \\
\hline $\begin{array}{l}\mathrm{R} \$ 2040,00 \\
5100,00\end{array}$ & 65,22 & 66,67 & 57,89 & 65,00 & 50,00 & 46,15 & 23,08 & 46,15 & 44,44 & 27,27 & 51,61 \\
\hline $\begin{array}{l}\mathrm{R} \$ 5100,00 \quad \mathrm{a} \\
10200,00\end{array}$ & 4,35 & 0,00 & 26,32 & 25,00 & 20,00 & 23,08 & 46,15 & 15,38 & 44,44 & 45,45 & 23,87 \\
\hline Acima de $\mathrm{R} \$ 10200,00$ & 0,00 & 6,67 & 0,00 & 0,00 & 20,00 & 0,00 & 15,38 & 0,00 & 0,00 & 9,09 & 3,87 \\
\hline
\end{tabular}

\subsection{ANÁLISE DA CONSISTÊNCIA INTERNA}

Foram realizados testes Alfa de Cronbach para a validação dos fatores, analisando a consistência das variáveis e confiabilidade dos constructos, considerando o critério de Alfa superior a 0,7 como definidor de fidedignidade aceitável (Hair et al.,2005). Os valores obtidos são superiores a 0,732 em todos os constructos, corroborando sua confiabilidade. As variáveis correspondentes a cada constructo, com os respectivos valores de Alfa, estão na tabela 2:

Tabela 2 Alfas de Cronbach dos constructos

\begin{tabular}{l|l|l}
\hline Constructos & Variáveis & Alfa \\
\hline Professores & $01,02,03,04,05,06,07,08,09$ & 0,841 \\
\hline Tutores Presenciais & $10,11,12,13,14,15,16,17$ & 0,932 \\
\hline Tutores a Distância & $18,19,20,21,22,23,24,25,26$ & 0,911 \\
\hline Coordenação de Curso e Polo & $27,28,29$ & 0,923 \\
\hline Sistema de Ensino & $30,31,32,33,34,35$ & 0,846 \\
\hline Participação em Atividades Acadêmicas & $36,37,38,39,40$ & 0,811 \\
\hline Organização do Curso & $41,42,43,44$ & 0,782 \\
\hline Expectativas referentes à Conhecimento e Empregabilidade & $45,46,47,48,49,50$ & 0,854 \\
\hline Condições do Polo & $51,52,53,54,55,56,57,58,59$ & 0,919 \\
\hline Suporte Acadêmico/Técnico & $60,61,62,63$ & 0,732 \\
\hline Tecnologias de Informação e Comunicação (TIC's) & $64,65,66,67$ & 0,805 \\
\hline
\end{tabular}

A tabela 2 apresenta a confiabilidade do constructo. Por exemplo, o constructo Professores corresponde à média das variáveis 01, 02, 03, 04, 05, 06, 07, 08, 09, com Alfa $=$ 0,841 . 


\subsection{ANÁLISE DESCRITIVA E COMPARATIVA DAS DIMENSÕES}

A seguir, foi aplicado o instrumento com os constructos organizados em diferentes variáveis nos polos em que ocorreu a oferta. Uma síntese dos resultados está na tabela 3.

Tabela 3 Diferença de média dos constructos, por polo e total

\begin{tabular}{c|c|c|c|c|c|c|c|c|c|c|c}
\hline Constructo & $\begin{array}{c}\text { Polo } \\
\mathbf{1}\end{array}$ & $\begin{array}{c}\text { Polo } \\
\mathbf{2}\end{array}$ & $\begin{array}{c}\text { Polo } \\
\mathbf{3}\end{array}$ & $\begin{array}{c}\text { Polo } \\
\mathbf{4}\end{array}$ & $\begin{array}{c}\text { Polo } \\
\mathbf{5}\end{array}$ & $\begin{array}{c}\text { Polo } \\
\mathbf{6}\end{array}$ & $\begin{array}{c}\text { Polo } \\
\mathbf{7}\end{array}$ & $\begin{array}{c}\text { Polo } \\
\mathbf{8}\end{array}$ & $\begin{array}{c}\text { Polo } \\
\mathbf{9}\end{array}$ & $\begin{array}{c}\text { Polo } \\
\mathbf{1 0}\end{array}$ & $\begin{array}{c}\text { Média } \\
\text { Total }\end{array}$ \\
\hline Professores & 3,55 & 3,99 & 3,49 & 3,22 & 3,72 & $4,12^{*}$ & 3,51 & 3,72 & 3,66 & 3,29 & 3,61 \\
\hline Tutores Presenciais & 3,95 & 4,09 & 4,30 & 3,71 & 4,24 & $4,44^{*}$ & 3,83 & 4,37 & 3,80 & 3,81 & 4,03 \\
\hline Tutores a Distância & 3,73 & 4,14 & 4,27 & 3,27 & 4,21 & 3,93 & 3,85 & $4,37 *$ & 3,79 & 3,58 & 3,88 \\
\hline $\begin{array}{c}\text { Coordenação de Curso } \\
\text { e Polo }\end{array}$ & 3,11 & $4,24^{*}$ & 4,07 & 3,55 & 3,40 & 4,05 & 3,34 & 4,00 & 3,38 & 3,47 & 3,65 \\
\hline $\begin{array}{c}\text { Sistema de Ensino } \\
\text { Participação em } \\
\text { Atividades } \\
\text { Acadêmicas }\end{array}$ & 3,75 & 3,84 & 3,69 & 3,82 & 3,63 & $4,29^{*}$ & 3,66 & 3,99 & 3,73 & 3,31 & 3,78 \\
\hline Organização do Curso & 3,07 & 3,30 & 3,47 & 3,29 & 3,26 & $3,94^{*}$ & 2,90 & 3,58 & 3,52 & 2,75 & 3,39 \\
\hline $\begin{array}{c}\text { Expectativas } \\
\text { Referentes à } \\
\text { Conhecimento e } \\
\text { Empregabilidade }\end{array}$ & 3,89 & 4,18 & 4,14 & 3,76 & 3,77 & $4,21^{*}$ & 3,49 & 4,17 & 4,05 & 3,56 & 3,94 \\
\hline Condições do Polo & 3,71 & 3,97 & $4,18 *$ & 3,53 & 3,99 & 3,33 & 3,91 & 3,65 & 3,65 & 3,96 & 3,78 \\
\hline $\begin{array}{c}\text { Suporte } \\
\text { Acadêmico/Técnico }\end{array}$ & 3,67 & $3,88^{*}$ & 3,44 & 3,52 & 3,67 & 3,66 & 3,53 & 3,59 & 3,62 & 3,74 & 3,62 \\
\hline $\begin{array}{c}\text { Tecnologias de } \\
\text { Informação e }\end{array}$ & 3,94 & 4,18 & 3,88 & 3,91 & 4,10 & $4,56^{*}$ & 3,61 & 4,25 & 4,13 & 3,72 & 4,03 \\
Comunicação (TIC’s)
\end{tabular}

*Maiores médias

Na tabela 3, é possível observar:

- Araranguá (Polo 1) obteve a menor média em Coordenação de Curso e Polo $(3,11)$.

- Canoinhas (Polo 2) teve maiores médias para Coordenação de Curso e Polo $(4,22)$, Organização do Curso $(4,08)$ e Suporte Acadêmico/Técnico $(3,88)$.

- Chapecó (Polo 3) apresentou a maior média para Condições do Polo $(4,18)$ e a menor média para o Suporte Acadêmico/Técnico $(3,44)$.

- Criciúma (Polo 4) teve a menor média em Professores $(3,22)$, Tutores Presenciais $(3,71)$, Tutores a Distância $(3,27)$ e Organização do Curso $(3,01)$.

- Joinville (Polo 6) teve maiores médias em Professores $(4,12)$, Tutores Presenciais $(4,44)$, Sistema de Ensino (4,29), Participação em Atividades Acadêmicas $(3,94)$, Expectativas Referentes à Conhecimento e Empregabilidade $(4,21)$ e TIC's $(4,56)$, com menor média para as Condições do Polo $(3,33)$. 


\section{AVALIAÇÃO DE CURSOS DE GRADUAÇÃO NA MODALIDADE A DISTÂNCIA: UMA EXPERIÊNCIA \\ NO CURSO DE GRADUAÇÃO EM ADMINISTRAÇÃO DA UNIVERSIDADE FEDERAL DE SANTA CATARINA \\ DOI: http://dx.doi.org/10.5007/1983-4535.2014v7n1p191}

- Lages (Polo 7) obteve as menores médias para Expectativas Referentes à Conhecimento e Empregabilidade $(3,49)$ e TIC's $(3,61)$.

- Laguna (Polo 8) apresenta maior média para Tutores a Distância $(4,37)$.

- Tubarão (Polo 10) teve médias mais baixas em Sistema de Ensino (3,31) e Participação em Atividades Acadêmicas (2,75).

A seguir, foi aplicado o teste não-paramétrico Kruskal Wallis para testar a existência de diferenças entre os polos em cada constructo. Este teste não exige suposições, tais como normalidade dos dados e homogeneidade de variâncias, a serem satisfeitas para validação de resultados. Suporte Acadêmico/Técnico não teve diferença significativa entre as médias dos polos pesquisados (p-valor $=0,303$ ). Nos demais, adotou-se o teste de Dunn para as comparações múltiplas. A tabela 4 apresenta o Teste de Dunn no constructo Professores:

Tabela 4 do Teste de Dunn para comparações múltiplas no constructo Professores

\begin{tabular}{|c|c|c|c|c|c|}
\hline \multirow{2}{*}{ Polo } & \multicolumn{5}{|c|}{ Professores } \\
\hline & \multicolumn{5}{|c|}{ Média } \\
\hline Joinville & 4,12 & $\mathrm{~A}$ & & & \\
\hline Canoinhas & 3,99 & $\mathrm{~A}$ & $\mathrm{~B}$ & & \\
\hline Florianópolis & 3,72 & & B & $\mathrm{C}$ & \\
\hline Laguna & 3,72 & & B & $\mathrm{C}$ & \\
\hline Palhoça & 3,66 & & & $\mathrm{C}$ & \\
\hline Araranguá & 3,55 & & & $\mathrm{C}$ & \\
\hline Lages & 3,51 & & & $\mathrm{C}$ & \\
\hline Chapecó & 3,49 & & & $\mathrm{C}$ & \\
\hline Tubarão & 3,29 & & & & $\mathrm{D}$ \\
\hline Criciúma & 3,22 & & & & $\mathrm{D}$ \\
\hline
\end{tabular}

A maior média $(4,12)$ é de Joinville e a menor média $(3,22)$ em Criciúma. A média de Joinville é significativamente maior que as demais, com exceção de Canoinhas. Não há diferença significativa entre Tubarão e Criciúma, que apresentaram as médias mais baixas.

A Tabela 5 apresenta o Teste de Dunn para Tutores Presenciais:

Tabela 5 do Teste de Dunn para comparações múltiplas no constructo Tutores Presenciais

\begin{tabular}{l|l|l|l|l}
\hline \multirow{2}{*}{ Polo } & \multicolumn{4}{l}{ Tutores Presenciais } \\
\cline { 2 - 5 } & \multicolumn{3}{l}{ Média } \\
\hline Joinville & 4,44 & A & & \\
\hline Laguna & 4,37 & A & & \\
\hline Chapecó & 4,30 & A & & \\
\hline Florianópolis & 4,24 & A & B & \\
\hline Canoinhas & 4,09 & & B & C \\
\hline Araranguá & 3,95 & & B & C \\
\hline
\end{tabular}




\section{AVALIAÇÃO DE CURSOS DE GRADUAÇÃO NA MODALIDADE A DISTÂNCIA: UMA EXPERIÊNCIA NO CURSO DE GRADUAÇÃO EM ADMINISTRAÇÃO DA UNIVERSIDADE FEDERAL DE SANTA CATARINA \\ DOI: http://dx.doi.org/10.5007/1983-4535.2014v7n1p191}

\begin{tabular}{l|l|l|l|l}
\hline Lages & 3,83 & & & $\mathrm{C}$ \\
\hline Tubarão & 3,81 & & & $\mathrm{C}$ \\
\hline Palhoça & 3,80 & & & $\mathrm{C}$ \\
\hline Criciúma & 3,71 & & & $\mathrm{C}$ \\
\hline
\end{tabular}

A maior média $(4,44)$ é de Joinville, que difere significativamente da menor média $(3,71)$ em Criciúma, assim como em Canoinhas, Araranguá, Lages, Tubarão e Palhoça.

Com relação ao constructo Tutores a distância:

Tabela 6 do Teste de Dunn para comparações múltiplas no constructo Tutores a Distância

\begin{tabular}{|c|c|c|c|c|c|c|c|c|}
\hline \multirow{3}{*}{$\begin{array}{l}\text { Polo } \\
\text { Laguna } \\
\end{array}$} & \multicolumn{8}{|c|}{ Tutores a Distância } \\
\hline & \multicolumn{8}{|c|}{ Média } \\
\hline & 4,37 & $\mathrm{~A}$ & & & & & & \\
\hline Chapecó & 4,27 & $\mathrm{~A}$ & $\mathrm{~B}$ & & & & & \\
\hline Florianópolis & 4,21 & $\mathrm{~A}$ & $\mathrm{~B}$ & $\mathrm{C}$ & & & & \\
\hline Canoinhas & 4,14 & & $\mathrm{~B}$ & $\mathrm{C}$ & & & & \\
\hline Joinville & 3,93 & & & $\mathrm{C}$ & $\mathrm{D}$ & & & \\
\hline Lages & 3,85 & & & & $\mathrm{D}$ & $\mathrm{E}$ & & \\
\hline Palhoça & 3,79 & & & & $\mathrm{D}$ & $\mathrm{E}$ & $\mathrm{F}$ & \\
\hline Araranguá & 3,73 & & & & & $\mathrm{E}$ & $\mathrm{F}$ & \\
\hline Tubarão & 3,58 & & & & & & $\mathrm{~F}$ & $\mathrm{G}$ \\
\hline Criciúma & 3,27 & & & & & & & $\mathrm{G}$ \\
\hline
\end{tabular}

A maior média $(4,37)$ é do Polo de Lages e a menor $(3,27)$ em Criciúma. Para este constructo, a média em Laguna é significativamente maior que a dos outros polos, com exceção de Chapecó e Florianópolis. Não há diferença significativa entre Tubarão e Criciúma, com as médias mais baixas.

Com relação ao constructo Coordenação de Curso e Polo:

Tabela 7 Teste de Dunn para comparações múltiplas em Coordenação de Curso e Polo

\begin{tabular}{l|l|l|l|l|l}
\hline \multirow{2}{*}{ Polo } & \multicolumn{6}{|l}{ Coordenação de Curso e Polo } \\
\cline { 2 - 7 } & \multicolumn{2}{|l}{ Média } & \multicolumn{4}{l}{} \\
\hline Canoinhas & 4,24 & $\mathrm{~A}$ & & & \\
\hline Chapecó & 4,07 & $\mathrm{~A}$ & & & \\
\hline Joinville & 4,05 & $\mathrm{~A}$ & $\mathrm{~B}$ & & \\
\hline Laguna & 4,00 & $\mathrm{~A}$ & $\mathrm{~B}$ & & \\
\hline Criciúma & 3,55 & & $\mathrm{~B}$ & $\mathrm{C}$ & \\
\hline Tubarão & 3,47 & & & $\mathrm{C}$ & $\mathrm{D}$ \\
\hline Florianópolis & 3,40 & & & $\mathrm{C}$ & $\mathrm{D}$ \\
\hline Palhoça & 3,38 & & & $\mathrm{C}$ & $\mathrm{D}$ \\
\hline Lages & 3,34 & & & $\mathrm{C}$ & $\mathrm{D}$ \\
\hline Araranguá & 3,11 & & & & $\mathrm{D}$ \\
\hline
\end{tabular}




\section{AVALIAÇÃO DE CURSOS DE GRADUAÇÃO NA MODALIDADE A DISTÂNCIA: UMA EXPERIÊNCIA \\ NO CURSO DE GRADUAÇÃO EM ADMINISTRAÇÃO DA UNIVERSIDADE FEDERAL DE SANTA CATARINA \\ DOI: http://dx.doi.org/10.5007/1983-4535.2014v7n1p191}

Em Coordenação de Curso e Polo, é possível destacar que a maior média encontrada $(4,24)$ é em Canoinhas e esta difere significativamente da menor média $(3,11)$, de Araranguá, assim como também dos polos de Criciúma, Tubarão, Florianópolis, Palhoça e Lages.

Com relação ao constructo Sistema de Ensino:

Tabela 8 Teste de Dunn de comparações múltiplas para Sistema de Ensino

\begin{tabular}{l|l|l|l|l|l}
\hline \multirow{2}{*}{ Polo } & \multicolumn{5}{|l}{ Sistema de Ensino } \\
\cline { 2 - 6 } & Média & \multicolumn{4}{l}{} \\
\hline Joinville & 4,29 & $\mathrm{~A}$ & & & \\
\hline Laguna & 3,99 & & $\mathrm{~B}$ & & \\
\hline Canoinhas & 3,84 & & $\mathrm{~B}$ & $\mathrm{C}$ & \\
\hline Criciúma & 3,82 & & $\mathrm{~B}$ & $\mathrm{C}$ & \\
\hline Araranguá & 3,75 & & $\mathrm{~B}$ & $\mathrm{C}$ & \\
\hline Palhoça & 3,73 & & $\mathrm{~B}$ & $\mathrm{C}$ & \\
\hline Chapecó & 3,69 & & & $\mathrm{C}$ & \\
\hline Lages & 3,66 & & & $\mathrm{C}$ & \\
\hline Florianópolis & 3,63 & & & $\mathrm{C}$ & $\mathrm{D}$ \\
\hline Tubarão & 3,31 & & & & $\mathrm{D}$ \\
\hline
\end{tabular}

Em Sistema de Ensino, é possível destacar que a maior média $(4,29)$ é do Polo de Joinville e a menor média $(3,31)$ em Tubarão. Para este constructo, a média em Joinville é significativamente maior que a de todos os outros polos. Além disso, não há diferença significativa entre os polos de Tubarão e Florianópolis, com as médias mais baixas.

Com relação ao constructo Participação em Atividades Acadêmicas:

Tabela 9 Teste de Dunn de comparações múltiplas em Participação em Atividades Acadêmicas

\begin{tabular}{l|l|l|l|l}
\hline \multirow{2}{*}{ Polo } & \multicolumn{4}{|l}{ Participação em Atividades Acadêmicas } \\
\cline { 2 - 5 } & Média & A & & \\
\hline Joinville & 3,94 & & B & \\
\hline Laguna & 3,58 & & B & \\
\hline Palhoça & 3,52 & & B & \\
\hline Araranguá & 3,51 & B & \\
\hline Chapecó & 3,47 & & B & \\
\hline Canoinhas & 3,30 & & B & \\
\hline Criciúma & 3,29 & & B & \\
\hline Florianópolis & 3,26 & & & $\mathrm{C}$ \\
\hline Lages & 2,90 & & & $\mathrm{C}$ \\
\hline Tubarão & 2,75 & & & \\
\hline
\end{tabular}

Em Participação em Atividades Acadêmicas, a maior média $(3,94)$ é em Joinville e a menor média $(2,75)$ em Tubarão. Não há diferença significativa entre os polos de Tubarão, Lages e Florianópolis, que apresentaram as médias mais baixas.

Com relação ao constructo Organização do Curso: 
Tabela 10 Teste de Dunn para comparações múltiplas para Organização do Curso

\begin{tabular}{l|l|l|l|l|l}
\hline \multirow{2}{*}{ Polo } & \multicolumn{5}{|l}{ Organização do Curso } \\
\cline { 2 - 7 } & Média & \multicolumn{4}{l}{} \\
\hline Canoinhas & 4,08 & A & & & \\
\hline Joinville & 4,05 & A & & & \\
\hline Laguna & 3,86 & A & & & \\
\hline Chapecó & 3,81 & A & B & & \\
\hline Palhoça & 3,53 & & B & C & \\
\hline Florianópolis & 3,52 & & B & C & \\
\hline Tubarão & 3,44 & & B & C & D \\
\hline Lages & 3,24 & & & C & D \\
\hline Araranguá & 3,07 & & & & D \\
\hline Criciúma & 3,01 & & & & D \\
\hline
\end{tabular}

No constructo Organização do Curso, é possível destacar que a maior média encontrada $(4,08)$ é do Polo de Canoinhas e esta difere significativamente da menor média encontrada $(3,01)$, do Polo de Criciúma, assim como também dos polos de Palhoça, Florianópolis, Tubarão, Lages e Araranguá.

Com relação a Expectativas Referentes à Conhecimento e Empregabilidade:

Tabela 11 Teste de Dunn de comparações múltiplas para Expectativas Referentes à Conhecimento e Empregabilidade

\begin{tabular}{l|l|l|l|l|l|l}
\hline \multirow{2}{*}{ Polo } & \multicolumn{5}{l}{$\begin{array}{l}\text { Expectativas Referentes à Conhecimento e } \\
\text { Empregabilidade }\end{array}$} \\
\hline & Média & \multicolumn{5}{l}{} \\
\hline Joinville & 4,21 & $\mathrm{~A}$ & & & & \\
\hline Canoinhas & 4,18 & $\mathrm{~A}$ & & & & \\
\hline Laguna & 4,17 & $\mathrm{~A}$ & & & & \\
\hline Chapecó & 4,14 & $\mathrm{~A}$ & & & & \\
\hline Palhoça & 4,05 & $\mathrm{~A}$ & $\mathrm{~B}$ & & & \\
\hline Araranguá & 3,89 & & $\mathrm{~B}$ & $\mathrm{C}$ & & \\
\hline Florianópolis & 3,77 & & $\mathrm{~B}$ & $\mathrm{C}$ & & \\
\hline Criciúma & 3,76 & & & $\mathrm{C}$ & $\mathrm{D}$ & \\
\hline Tubarão & 3,56 & & & & $\mathrm{D}$ & $\mathrm{E}$ \\
\hline Lages & 3,49 & & & & & $\mathrm{E}$ \\
\hline
\end{tabular}

Nas Expectativas Referentes à Conhecimento e Empregabilidade, é possível destacar que a maior média encontrada $(4,21)$ é em Joinville, que difere significativamente da menor média $(3,49)$, em Lages, assim como também dos polos de Araranguá, Florianópolis, Criciúma e Tubarão.

Com relação às Condições do Polo: 
Tabela 12 Teste de Dunn de comparações múltiplas para Condições do Polo

\begin{tabular}{l|l|l|l|l|l}
\hline \multirow{2}{*}{ Polo } & \multicolumn{5}{l}{ Condições do Polo } \\
\cline { 2 - 7 } & Média & \multicolumn{4}{l}{} \\
\hline Chapecó & 4,18 & A & & & \\
\hline Florianópolis & 3,99 & A & B & & \\
\hline Canoinhas & 3,97 & A & B & & \\
\hline Tubarão & 3,96 & A & B & & \\
\hline Lages & 3,91 & & B & & \\
\hline Araranguá & 3,71 & & B & C & \\
\hline Laguna & 3,65 & & & C & D \\
\hline Palhoça & 3,65 & & & C & D \\
\hline Criciúma & 3,53 & & & C & D \\
\hline Joinville & 3,33 & & & & D \\
\hline
\end{tabular}

Para o constructo Condições do Polo, a maior média encontrada $(4,18)$ é de Chapecó e difere significativamente da menor média $(3,33)$, de Joinville, assim como também dos polos de Lages, Araranguá, Laguna, Palhoça e Criciúma.

Com relação ao constructo Tecnologias de Informação e Comunicação (TIC1s):

Tabela 13 Teste de Dunn para comparações múltiplas para TIC'S

\begin{tabular}{l|l|l|l|l|l|l}
\hline \multirow{2}{*}{ Polo } & \multicolumn{5}{|l}{ Tecnologias de Informação e Comunicação (TIC's) } \\
\hline & Média & \multicolumn{5}{l}{} \\
\hline Joinville & 4,56 & $\mathrm{~A}$ & & & & \\
\hline Laguna & 4,25 & & $\mathrm{~B}$ & & & \\
\hline Canoinhas & 4,18 & & $\mathrm{~B}$ & $\mathrm{C}$ & & \\
\hline Palhoça & 4,13 & & $\mathrm{~B}$ & $\mathrm{C}$ & & \\
\hline Florianópolis & 4,10 & & $\mathrm{~B}$ & $\mathrm{C}$ & & \\
\hline Araranguá & 3,94 & & $\mathrm{~B}$ & $\mathrm{C}$ & $\mathrm{D}$ & \\
\hline Criciúma & 3,91 & & & $\mathrm{C}$ & $\mathrm{D}$ & $\mathrm{E}$ \\
\hline Chapecó & 3,88 & & & $\mathrm{C}$ & $\mathrm{D}$ & $\mathrm{E}$ \\
\hline Tubarão & 3,72 & & & & $\mathrm{D}$ & $\mathrm{E}$ \\
\hline Lages & 3,61 & & & & & $\mathrm{E}$ \\
\hline
\end{tabular}

Em Tecnologias de Informação e Comunicação (TIC's), a maior média $(4,56)$ é do Polo de Joinville e a menor média $(3,61)$ em Lages. Para este constructo a média encontrada em Joinville é significativamente maior que a de todos os outros polos. Além disso, não há diferença significativa entre os polos de Lages, Tubarão, Chapecó e Criciúma, que apresentaram as médias mais baixas.

\subsection{INFLUÊNCIA DOS CONSTRUTOS NA AVALIAÇÃO DO CURSO}

A fim de verificar a existência de relação entre os constructos, calculou-se o Coeficiente de Correlação de Pearson, cujos resultados são apresentados na Tabela 14. De 


\section{AVALIAÇÃO DE CURSOS DE GRADUAÇÃO NA MODALIDADE A DISTÂNCIA: UMA EXPERIÊNCIA \\ NO CURSO DE GRADUAÇÃO EM ADMINISTRAÇÃO DA UNIVERSIDADE FEDERAL DE SANTA CATARINA \\ DOI: http://dx.doi.org/10.5007/1983-4535.2014v7n1p191}

acordo com Pestana e Gageiro (2003, p. 189), o "coeficiente de correlação $R$ de Pearson é uma medida de associação linear entre variáveis quantitativas e varia entre -1 e 1". A existência da correlação indica que a intensidade de um fenômeno é acompanhada tendencialmente por outro, embora eles não sejam indissoluvelmente ligados. Por convenção, os autores sugerem que $R<0,2=$ associação muito baixa; $R$ entre 0,2 e $0,39=$ associação baixa; $R$ entre 0,4 e $0,69=$ associação moderada; $R$ entre 0,7 e $0,89=$ associação alta; e $R$ entre 0,9 e 1 = associação muito alta (PESTANA; GAGEIRO, 2003).

De um modo geral, os dados demonstram as maiores correlações entre o constructo Tutores a Distância com o constructo Professores $(R=0,445)$ e, também, com os Tutores Presenciais $(R=0,437)$, indicando que quanto melhor a percepção de um, também é melhor a percepção do outro.

O constructo Sistema de Ensino obteve a terceira maior correlação positiva encontrada com a dimensão Professores $(R=0,385)$. A quarta maior correlação positiva foi obtida pelo constructo Expectativas referentes à Conhecimento e Empregabilidade com a dimensão Organização do Curso $(R=0,381)$.

As correlações que não foram significativas ao nível de $1 \%$ foram entre o constructo Condições do Polo com a Participação em Atividades Acadêmicas $(\mathrm{R}=0,053)$ e com as Expectativas referentes à Conhecimento e Empregabilidade $(\mathrm{R}=0,043)$, indicando que não necessariamente quanto melhor a percepção das Condições do Polo melhor será a percepção da Participação em Atividades Acadêmicas e das Expectativas referentes à Conhecimento e Empregabilidade e vice-versa.

Tabela 14 Matriz de correlação entre os constructos

\begin{tabular}{c|c|c|c|c|c|c|c|c|c|c}
\hline Constructo & $\mathbf{2}$ & $\mathbf{3}$ & $\mathbf{4}$ & $\mathbf{5}$ & $\mathbf{6}$ & $\mathbf{7}$ & $\mathbf{8}$ & $\mathbf{9}$ & $\mathbf{1 0}$ & $\mathbf{1 1}$ \\
\hline $\mathbf{1}$ & $0,188^{*}$ & $0,445^{*}$ & $0,337^{*}$ & $0,385^{*}$ & $0,110^{*}$ & $0,168^{*}$ & $0,092^{*}$ & $0,240^{*}$ & $0,243^{*}$ & $0,192^{*}$ \\
\hline $\mathbf{2}$ & & $0,437^{*}$ & $0,252^{*}$ & $0,107^{*}$ & $0,297^{*}$ & $0,356^{*}$ & $0,224^{*}$ & $0,125^{*}$ & $0,235^{*}$ & $0,275^{*}$ \\
\hline $\mathbf{3}$ & & & $0,308^{*}$ & $0,218^{*}$ & $0,246^{*}$ & $0,316^{*}$ & $0,204^{*}$ & $0,107^{*}$ & $0,258^{*}$ & $0,260^{*}$ \\
\hline $\mathbf{4}$ & & & & $0,339^{*}$ & $0,183^{*}$ & $0,340^{*}$ & $0,343^{*}$ & $0,210^{*}$ & $0,311^{*}$ & $0,205^{*}$ \\
\hline $\mathbf{5}$ & & & & & $0,243^{*}$ & $0,235^{*}$ & $0,259^{*}$ & $0,258^{*}$ & $0,267^{*}$ & $0,332^{*}$ \\
\hline $\mathbf{6}$ & & & & & & $0,254^{*}$ & $0,350^{*}$ & 0,053 & $0,206^{*}$ & $0,330^{*}$ \\
\hline $\mathbf{7}$ & & & & & & & $0,381^{*}$ & $0,108^{*}$ & $0,161^{*}$ & $0,316^{*}$ \\
\hline $\mathbf{8}$ & & & & & & & & 0,043 & $0,167^{*}$ & $0,337^{*}$ \\
\hline $\mathbf{9}$ & & & & & & & & & $0,215^{*}$ & $0,173^{*}$ \\
\hline $\mathbf{1 0}$ & & & & & & & & & & $0,296^{*}$ \\
\hline
\end{tabular}

*Correlação é significativa ao nível de 0,01 .

Legenda: (1) Professores, (2) Tutores Presenciais, (3) Tutores a Distância, (4) Coordenação de Curso e Polo, (5) Sistema de Ensino, (6) Participação em Atividades Acadêmicas, (7) Organização do Curso, (8) Expectativas 


\section{AVALIAÇÃO DE CURSOS DE GRADUAÇÃO NA MODALIDADE A DISTÂNCIA: UMA EXPERIÊNCIA \\ NO CURSO DE GRADUAÇÃO EM ADMINISTRAÇÃO DA UNIVERSIDADE FEDERAL DE SANTA \\ DOI: http://dx.doi.org/10.5007/1983-4535.2014v7n1p191}

referentes à Conhecimento e Empregabilidade, (9) Condições do Polo, (10) Suporte Acadêmico/Técnico e (11) Tecnologias de Informação e Comunicação (TIC's).

\section{CONSIDERAÇÕES FINAIS}

Os resultados apurados através da aplicação junto aos polos do Curso de Graduação em Administração, modalidade a distância, na Universidade Federal de Santa Catarina permitiram validar o instrumento proposto na modalidade bacharelado. As dimensões pessoas, organização didático-pedagógica e instalações físicas e os constructos inerentes a cada dimensão permitiram apurar o grau de concordância e/ou discordância dos estudantes em relação aos mesmos.

Quanto à dimensão Pessoas, verificou-se que as médias atribuídas para todos os constructos foram superiores a 3,5 (considerando a escala 1 a 5), que indica que os estudantes estão satisfeitos com esta dimensão como um todo. Ressalta-se que o constructo referente a Coordenação de Curso e Coordenação de Polo recebeu a pior avaliação dos estudantes, embora seja um resultado que pode ser considerado como positivo $(3,65)$. Em especial, merece destaque o item referente ao feedback nos prazos previstos como o que recebeu menor pontuação $(3,03)$.

Os constructos que compõem a dimensão Organização Didático-Pedagógica apresentaram médias inferiores a 4, sendo aquela com menores pontuações. Assim, destacamse a participação em atividades acadêmicas $(3,39)$ e o item referente a integração com colegas em atividades sociais $(2,80)$ como aqueles que merecem observação.

Por fim, a dimensão referente às Instalações Físicas também apresentou média superior a 3,5. O suporte acadêmico/técnico foi o constructo que apresentou menor média $(3,62)$, onde o item referente aos treinamentos para ambientes de aprendizagem foi o que apresentou pior média $(3,18)$.

Destaca-se, ainda, que os estudantes pertencentes ao polo de Joinville estão significativamente mais satisfeitos que os pertencentes aos polos de Araranguá e Tubarão em todos os constructos, com exceção de Suporte Acadêmico/Técnico e Condições do Polo. O polo de Joinville também obteve média significativamente maior que o polo de Lages em todos os constructos, com exceção de Suporte Acadêmico/Técnico, Tutores a Distância e Condições do Polo. O polo de Canoinhas obteve média significativamente maior que os polos de Lages e Tubarão em todos os constructos, com exceção de Suporte Acadêmico/Técnico, Tutores Presenciais e Condições do Polo. 


\section{AVALIAÇÃO DE CURSOS DE GRADUAÇÃO NA MODALIDADE A DISTÂNCIA: UMA EXPERIÊNCIA \\ NO CURSO DE GRADUAÇÃO EM ADMINISTRAÇÃO DA UNIVERSIDADE FEDERAL DE SANTA CATARINA \\ DOI: http://dx.doi.org/10.5007/1983-4535.2014v7n1p191}

De um modo geral, é possível concluir que, no entender dos estudantes, a dimensão Organização Didático-Pedagógica e, nela, a questão específica da participação em atividades acadêmicas, é o item que merece atenção especial por parte da Coordenação do Curso, tendo em vista que este foi o único item com média menor do que 3,5.

Tem-se, assim um instrumento que vem auxiliar as instituições com uma ferramenta útil que permite a avaliação das condições de oferta dos cursos ministrados na modalidade a distância, apresentando coerência interna e adequação às recomendações do Ministério da Educação. O embasamento do referencial teórico e a aplicação prática permitiram concluir que o instrumento proposto é abrangente e possui potencial para ser utilizado na avaliação da educação a distância em Instituições de Ensino Superior, tanto as de natureza pública quanto privada.

\section{REFERÊNCIAS}

BRASIL. Lei $\mathbf{N}^{\mathbf{0}}$ 10.172, de 9 de janeiro de 2001. Aprova o Plano Nacional de Educação e dá outras providências.

Lei $\mathbf{N}^{\circ}$ 10.861, de 14 de abril de 2004. Institui o Sistema Nacional de Avaliação da Educação Superior - SINAES e dá outras providências.

Projeto de Lei $\mathbf{N}^{\circ} \mathbf{8 . 0 3 5}$, de 20 de dezembro de 2010. Aprova o Plano Nacional de Educação para o decênio 2011-2020 e dá outras providências.

FALLER, L. P. Estudo de parâmetros para a avaliação de cursos de ensino a distância (EAD). 2009. 165 f. (Mestrado em Administração). Universidade Federal de Santa Maria: Santa Maria, 2009.

GOMES, Alfredo M.; ROBERTSON, Susan L.; DALE, Roger. The social condition of higher education: globalisation and (beyond) regionalisation in Latin America. Globalisation, Societies \& Education, Oxon, v. 10, n. 2, p.221-245, jun. 2012.

IBGE - Instituto Brasileiro de Geografia e Estatística. Síntese de Indicadores Sociais: uma análise das condições de vida da população brasileira. Estudos e Pesquisas - Informação Demográfica e Socioeconômica, Rio de Janeiro, n. 29, 2012.

INEP - Instituto Nacional de Estudos e Pesquisas Educacionais Anísio Teixeira. Sinopse Estatística da Educação Superior - Graduação: 2001. Brasília: Inep, 2002?. Disponível em: <

http://download.inep.gov.br/download/censo/2001/Superior/Sinopse_Superior_2001.zip>. Acesso em: 12 ago. 2013. 
. Sinopse Estatística da Educação Superior - Graduação: 2011. Brasília: Inep, [2013]. Disponível em: <

http://download.inep.gov.br/informacoes_estatisticas/sinopses_estatisticas/sinopses_educacao _superior/sinopse_educacao_superior_2011.zip $>$. Acesso em: 12 ago. 2013.

LUCE, Maria Beatriz. Diversidade e diferenciação do público e do privado na Educação Superior do Brasil. In: LASA 2001 Congress, 2001, Washington DC. LASA 2001 Online Papers. Pittsburg: LASA (Latin American Studies Association), 2001. Disponível em: $<$ http://lasa.international.pitt.edu/Lasa2001/Luce.pdf>. Acesso em: 10 ago. 2013.

PESTANA, M. H.; GAGEIRO, J. N. Análise de dados para ciências sociais: a complementaridade do SPSS. 3. ed. Lisboa: Sílabo, 2003.

RAMA, Claudio. Tipología de las tendencias de la virtualización de la educación superior en América Latina. Revista Diálogo Educacional, Curitiba, v. 8, n. 24, p. 341-355, mai./ago. 2008

. La reforma de la virtualización de la universidad: El nacimiento de la educación digital. Guadalajara: UDGVirtual, 2012.

RODRIGUES, Cláudia Medianeira Cruz; MIORANDO, Bernardo Sfredo. Instrumento de Avaliação para Cursos de Educação a Distância. In: Denise Leite; Cleoni Barboza Fernandes; Cecilia Luiza Broilo (Orgs.). Qualidade da Educação Superior: Avaliação e Implicações para o Futuro da Universidade. Porto Alegre: EDIPUCRS, 2012, p. 45-50.

SILVIO, José. La virtualización de la educación superior: alcances, posibilidades y limitaciones. Educación Superior y Sociedad, Caracas, v. 9, n. 1, p. 27-50, 1998.

\section{Apêndice A}

\section{1 - DADOS DE IDENTIFICAÇÃO}

1.1 Qual seu Curso?

1.2 Qual polo você pertence:

1.3 Qual a distância da sua casa até o polo?

1.4 Ano de Ingresso no Curso:

1.5 Idade: anos

1.6 Sexo: ( ) Feminino ( ) Masculino

1.7 Estado Civil:

( ) Casado(a) ( ) Solteiro(a) ( ) Separado(a)/desquitado(a)/divorciado(a)

( ) Viúvo(a) ( ) Outro

1.8 Quantos filhos você tem?

( ) Nenhum.

( ) Um.

( ) Dois.

( ) Três.

( ) Quatro ou mais.

1.9 Em que você trabalha atualmente? (Marque apenas uma resposta) 


\section{AVALIAÇÃO DE CURSOS DE GRADUAÇÃO NA MODALIDADE A DISTÂNCIA: UMA EXPERIÊNCIA NO CURSO DE GRADUAÇÃO EM ADMINISTRAÇÃO DA UNIVERSIDADE FEDERAL DE SANTA

( ) Na agricultura, no campo, na fazenda ou na pesca.

( ) Na indústria.

( ) Na construção civil.

( ) No comércio, banco, transporte, hotelaria ou outros serviços.

( ) Como funcionário(a) do governo federal, estadual ou municipal.

( ) Como profissional liberal, professor(a) ou técnico(a) de nível superior.

( ) Outro.

( ) Não trabalho.

1.10 Faixa mensal de renda familiar:

( ) De R\$ 0 a R \$ 1.020,00 (até 2 S.M).

( ) De R\$1.020,00 a R \$ 2.040,00 (entre 2 e 4 S.M).

( ) De R\$2.040,00 a R\$5.100,00 (entre 4 e 10 S.M).

( ) De R\$ 5.100,00 a R\$ 10.200,00(entre 10 e 20 S.M).

( ) Acima de R\$10.200,00 (acima de 20 S.M).

1.11 Quantas horas semanais você trabalha?

( ) Sem jornada fixa, até 10 horas semanais.

( ) De 11 a 20 horas semanais.

( ) De 21 a 30 horas semanais.

( ) De 31 a 40 horas semanais.

( ) Mais de 40 horas semanais.

1.12 Quantas horas semanais você dedica aos estudos?

( ) Sem jornada fixa, até 10 horas semanais.

( ) De 11 a 20 horas semanais.

( ) De 21 a 30 horas semanais.

( ) De 31 a 40 horas semanais.

( ) Mais de 40 horas semanais.

1.13 Qual o seu domínio do uso de informática antes de ingressar no curso:

( ) Ótimo ( ) Bom ( ) Regular ( ) Ruim ( ) Péssimo

1.14 Você possui computador em casa?

( ) Sim ( ) Não

1.15 Seu computador possui acesso à internet?

( ) Sim ( ) Não

\section{INSTRUÇÕES DE PREENCHIMENTO:}

Para responder ao questionário, utilize a escala abaixo representada:

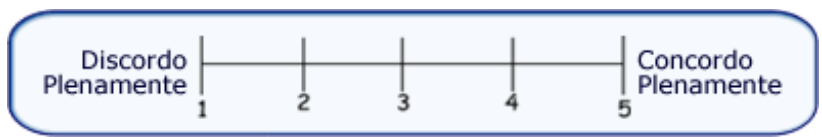

\section{2 - CORPO DOCENTE, CORPO DE TUTORES E COORDENAÇÃO}

2.1 - Os professores...

\begin{tabular}{|c|c|c|c|c|c|c|c|}
\hline $\mathbf{N}^{\mathbf{o}}$ & Questão & \multicolumn{3}{|c|}{$\begin{array}{l}\text { Discordo } \\
\text { plenamente }\end{array}$} & \multicolumn{2}{|c|}{$\begin{array}{l}\text { Concordo } \\
\text { plenamente }\end{array}$} & \multirow[t]{2}{*}{$\begin{array}{l}\text { Não se } \\
\text { aplica }\end{array}$} \\
\hline 01 & demonstram domínio teórico sobre o conteúdo. & 1 & 2 & 3 & 4 & 5 & \\
\hline 02 & demonstram domínio prático sobre o conteúdo, relacionando-o com a realidade. & 1 & 2 & 3 & 4 & 5 & \\
\hline 03 & esclarecem minhas dúvidas. & 1 & 2 & 3 & 4 & 5 & \\
\hline 04 & interagem com os alunos. & 1 & 2 & 3 & 4 & 5 & \\
\hline 05 & demonstram interesse no meu aprendizado. & 1 & 2 & 3 & 4 & 5 & \\
\hline 06 & fornecem retorno das atividades realizadas nos prazos previstos. & 1 & 2 & 3 & 4 & 5 & \\
\hline 07 & demonstram domínio das tecnologias de informação e comunicação utilizadas no curso. & 1 & 2 & 3 & 4 & 5 & \\
\hline 08 & são assíduos e pontuais. & 1 & 2 & 3 & 4 & 5 & \\
\hline 09 & estimulam o relacionamento interpessoal. & 1 & 2 & 3 & 4 & 5 & \\
\hline
\end{tabular}

2.2 - Os Tutores Presenciais... 


\section{AVALIAÇÃO DE CURSOS DE GRADUAÇÃO NA MODALIDADE A DISTÂNCIA: UMA EXPERIÊNCIA NO CURSO DE GRADUAÇÃO EM ADMINISTRAÇÃO DA UNIVERSIDADE FEDERAL DE SANTA CATARINA \\ DOI: http://dx.doi.org/10.5007/1983-4535.2014v7n1p191}

\begin{tabular}{|l|l|}
\hline $\mathbf{N}^{\mathbf{0}}$ & Questão \\
\hline 10 & demonstram domínio teórico sobre o conteúdo. \\
\hline 11 & demonstram domínio prático sobre o conteúdo, relacionando-o com a realidade. \\
\hline 12 & esclarecem minhas dúvidas. \\
\hline 13 & interagem com os alunos. \\
\hline 14 & demonstram interesse pelo meu aprendizado. \\
\hline 15 & demonstram domínio das tecnologias de informação e comunicação utilizadas no curso. \\
\hline 16 & são assíduos e pontuais. \\
\hline 17 & estimulam o relacionamento interpessoal. \\
\hline
\end{tabular}

\section{3 - Os Tutores a Distância...}

\begin{tabular}{|c|c|}
\hline $\mathbf{N}^{\mathbf{0}}$ & Questão \\
\hline 18 & demonstram domínio teórico sobre o conteúdo. \\
\hline 19 & demonstram domínio prático sobre o conteúdo, relacionando-o com a realidade. \\
\hline 20 & esclarecem minhas dúvidas. \\
\hline 21 & interagem com os alunos. \\
\hline 22 & demonstram interesse pelo meu aprendizado. \\
\hline 23 & fornecem retorno das atividades realizadas nos prazos previstos. \\
\hline 24 & demonstram domínio das tecnologias de informação e comunicação utilizadas no curso. \\
\hline 25 & são assíduos e pontuais. \\
\hline 26 & estimulam o relacionamento interpessoal. \\
\hline
\end{tabular}

\begin{tabular}{|l|l|l|l|l|l|}
\hline $\begin{array}{l}\text { Discordo } \\
\text { plenamente }\end{array}$ & $\begin{array}{l}\text { Não se } \\
\text { aplica }\end{array}$ \\
\hline 1 & 2 & 3 & 4 & 5 & \\
\hline 1 & 2 & 3 & 4 & 5 & \\
\hline 1 & 2 & 3 & 4 & 5 & \\
\hline 1 & 2 & 3 & 4 & 5 & \\
\hline 1 & 2 & 3 & 4 & 5 & \\
\hline 1 & 2 & 3 & 4 & 5 & \\
\hline 1 & 2 & 3 & 4 & 5 & \\
\hline 1 & 2 & 3 & 4 & 5 & \\
\hline
\end{tabular}

2.4 - Coordenação de Curso e de Polo

\begin{tabular}{|c|c|c|c|c|c|c|c|}
\hline $\mathbf{N}^{\mathbf{0}}$ & Questão & & $\begin{array}{l}\text { ordo } \\
\text { amente }\end{array}$ & & n & & $\begin{array}{l}\text { Não se } \\
\text { aplica }\end{array}$ \\
\hline 27 & $\begin{array}{l}\text { A coordenação administrativa do Polo gerencia de modo adequado as diversas demandas dos } \\
\text { alunos e do curso. }\end{array}$ & 1 & 2 & 3 & 4 & 5 & \\
\hline 28 & $\begin{array}{l}\text { A coordenação pedagógica do Polo gerencia de modo adequado as diversas demandas dos } \\
\text { alunos e do curso. }\end{array}$ & 1 & 2 & 3 & 4 & 5 & \\
\hline 29 & $\begin{array}{l}\text { A coordenação do curso gerencia de modo adequado as diversas demandas dos alunos e do } \\
\text { curso. }\end{array}$ & 1 & 2 & 3 & 4 & 5 & \\
\hline
\end{tabular}

\section{3 - ORGANIZAÇÃO DIDÁTICO-PEDAGÓGICA}

3.1 - Sistema de Ensino

\begin{tabular}{|c|c|c|c|c|c|c|c|}
\hline $\mathbf{N}^{\mathbf{0}}$ & Questão & & $\begin{array}{l}\text { rdo } \\
\text { imente }\end{array}$ & & nat & & $\begin{array}{l}\text { Não se } \\
\text { aplica }\end{array}$ \\
\hline 30 & A estrutura curricular do curso é adequada aquilo que é requerido pelo mercado de trabalho. & 1 & 2 & 3 & 4 & 5 & \\
\hline 31 & As cargas horárias das disciplinas são bem dimensionadas. & 1 & 2 & 3 & 4 & 5 & \\
\hline 32 & A integração das disciplinas é organizada de modo adequado. & 1 & 2 & 3 & 4 & 5 & \\
\hline 33 & $\begin{array}{l}\text { O foco do curso se dá mais no desenvolvimento de competências e habilidades do que no } \\
\text { controle ( } \mathrm{n}^{\circ} \text { de acesso ao ambiente, datas de entregas de trabalhos, etc.). }\end{array}$ & 1 & 2 & 3 & 4 & 5 & \\
\hline 34 & $\begin{array}{l}\text { A avaliação da aprendizagem através de provas, acessos aos ambientes de aprendizagem, } \\
\text { etc. é desenvolvida de forma apropriada e promove o feedback contínuo. }\end{array}$ & 1 & 2 & 3 & 4 & 5 & \\
\hline 35 & As metodologias e dinâmicas de ensino são adequadas. & 1 & 2 & 3 & 4 & 5 & \\
\hline
\end{tabular}

\section{2 - Participação em Atividades Acadêmicas}

\begin{tabular}{|c|c|c|c|c|c|c|c|}
\hline \multirow{2}{*}{$\mathbf{N}^{\mathbf{0}}$} & \multirow{2}{*}{$\begin{array}{l}\text { Questão } \\
\text { Existe ampla possibilidade de interação com os colegas em atividades acadêmicas. }\end{array}$} & \multicolumn{2}{|c|}{$\begin{array}{l}\text { Discordo } \\
\text { plenamente }\end{array}$} & \multicolumn{3}{|c|}{$\begin{array}{l}\text { Concordo } \\
\text { plenamente }\end{array}$} & \multirow[t]{2}{*}{$\begin{array}{l}\text { Não se } \\
\text { aplica }\end{array}$} \\
\hline & & 1 & 2 & 3 & 4 & 5 & \\
\hline 37 & Existe ampla possibilidade de interação com os colegas em atividades sociais. & 1 & 2 & 3 & 4 & 5 & \\
\hline 38 & O tempo demandado pelo curso em estudos e trabalhos individuais é adequado. & 1 & 2 & 3 & 4 & 5 & \\
\hline 39 & O tempo demandado pelo curso em estudos e trabalhos em grupo é adequado. & 1 & 2 & 3 & 4 & 5 & \\
\hline 40 & As participações presenciais exigidas são adequadas. & 1 & 2 & 3 & 4 & 5 & \\
\hline
\end{tabular}
3.3 - Organização do Curso

\begin{tabular}{|l|l|}
\hline $\mathbf{N}^{\mathbf{o}}$ & Questão \\
\hline 41 & O Curso dá abertura para sugestões e opiniões sobre o trabalho que está sendo desenvolvido. \\
\hline 42 & Existe um clima de relacionamento amistoso entre professores, tutores e coordenadores. \\
\hline 43 & Existe respeito às regras, normas e compromissos estabelecidos pelo Curso. \\
\hline 44 & O Curso preocupa-se com a qualidade do aluno que está saindo para o mercado de trabalho. \\
\hline
\end{tabular}

\begin{tabular}{|l|l|}
\hline $\mathbf{N}^{\mathbf{0}}$ & Questão \\
\hline 45 & O Curso fornece a possibilidade de experimentar as práticas de trabalho. \\
\hline 46 & O Curso fornece a possibilidade de articular os conteúdos de sala de aula com a realidade. \\
\hline 47 & O Curso fornece a possibilidade de qualificar meu trabalho. \\
\hline 48 & O Curso fornece a possibilidade de melhorar meu currículo. \\
\hline
\end{tabular}

\begin{tabular}{|l|l|l|l|l|l|}
\hline $\begin{array}{l}\text { Discordo } \\
\text { plenamente }\end{array}$ & $\begin{array}{l}\text { Concordo } \\
\text { plenamente }\end{array}$ & $\begin{array}{l}\text { Não se } \\
\text { aplica }\end{array}$ \\
\hline 1 & 2 & 3 & 4 & 5 & \\
\hline 1 & 2 & 3 & 4 & 5 & \\
\hline 1 & 2 & 3 & 4 & 5 & \\
\hline 1 & 2 & 3 & 4 & 5 & \\
\hline
\end{tabular}

\begin{tabular}{|l|l|l|l|l|l|}
\hline $\begin{array}{l}\text { Discordo } \\
\text { plenamente }\end{array}$ & $\begin{array}{l}\text { Concordo } \\
\text { plenamente }\end{array}$ & $\begin{array}{l}\text { Não se } \\
\text { aplica }\end{array}$ \\
\hline 1 & 2 & 3 & 4 & 5 & \\
\hline 1 & 2 & 3 & 4 & 5 & \\
\hline 1 & 2 & 3 & 4 & 5 & \\
\hline 1 & 2 & 3 & 4 & 5 & \\
\hline
\end{tabular}




\section{AVALIAÇÃO DE CURSOS DE GRADUAÇÃO NA MODALIDADE A DISTÂNCIA: UMA EXPERIÊNCIA NO CURSO DE GRADUAÇÃO EM ADMINISTRAÇÃO DA UNIVERSIDADE FEDERAL DE SANTA CATARINA \\ DOI: http://dx.doi.org/10.5007/1983-4535.2014v7n1p191}

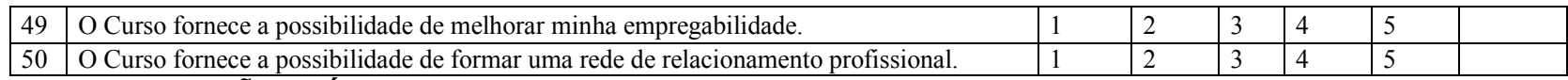

\section{4 - INSTALAÇÕES FÍSICAS}

4.1 - Condições do Polo

\begin{tabular}{|c|c|c|c|c|c|c|c|}
\hline $\mathbf{N}^{\mathbf{0}}$ & Questão & \multicolumn{2}{|c|}{$\begin{array}{l}\text { Discordo } \\
\text { plenamente }\end{array}$} & \multicolumn{3}{|c|}{$\begin{array}{l}\text { Concordo } \\
\text { plenamente }\end{array}$} & \multirow[t]{2}{*}{$\begin{array}{l}\text { Não se } \\
\text { aplica }\end{array}$} \\
\hline 51 & O polo é de fácil acesso. & 1 & 2 & 3 & 4 & 5 & \\
\hline 52 & Os horários de funcionamento do polo são adequados. & 1 & 2 & 3 & 4 & 5 & \\
\hline 53 & As salas de aula utilizadas em atividades presenciais são adequadas. & 1 & 2 & 3 & 4 & 5 & \\
\hline 54 & As instalações, funcionamento e acesso à biblioteca do polo são adequados. & 1 & 2 & 3 & 4 & 5 & \\
\hline 55 & O acervo disponível na Biblioteca atende às necessidades do Curso. & 1 & 2 & 3 & 4 & 5 & \\
\hline 56 & As instalações administrativas do polo são adequadas. & 1 & 2 & 3 & 4 & 5 & \\
\hline 57 & O espaço de convivência do polo é adequado. & 1 & 2 & 3 & 4 & 5 & \\
\hline 58 & Os equipamentos disponíveis nos polos são adequados. & 1 & 2 & 3 & 4 & 5 & \\
\hline 59 & Os laboratórios especializados no polo para realização das atividades são adequados. & 1 & 2 & 3 & 4 & 5 & \\
\hline
\end{tabular}

4.2 - Suporte Acadêmico/ Técnico

\begin{tabular}{|c|c|c|c|c|c|c|c|}
\hline $\mathbf{N}^{\mathbf{0}}$ & Questão & \multicolumn{3}{|c|}{$\begin{array}{l}\text { Discordo } \\
\text { plenamente }\end{array}$} & \multicolumn{2}{|c|}{$\begin{array}{l}\text { Concordo } \\
\text { plenamente }\end{array}$} & $\begin{array}{l}\text { Não se } \\
\text { aplica }\end{array}$ \\
\hline 60 & O suporte online é adequado. & 1 & 2 & 3 & 4 & 5 & \\
\hline 61 & O suporte presencial é adequado. & 1 & 2 & 3 & 4 & 5 & \\
\hline 62 & Existem treinamentos para capacitar no uso dos ambientes de aprendizagem. & 1 & 2 & 3 & 4 & 5 & \\
\hline 63 & A qualidade de acesso à internet do polo é adequada. & 1 & 2 & 3 & 4 & 5 & \\
\hline
\end{tabular}

4.3 - Tecnologias de Informação e Comunicação (TIC's)

\begin{tabular}{|c|c|c|c|c|c|c|c|}
\hline $\mathbf{N}^{\circ}$ & Questão & & do & & Im & & $\begin{array}{l}\text { Não se } \\
\text { aplica }\end{array}$ \\
\hline 64 & $\begin{array}{l}\text { Os materiais didáticos (impressos, audiovisuais e/ou para internet) são elaborados de forma } \\
\text { clara e compreensível, promovendo a autonomia de estudos. }\end{array}$ & 1 & 2 & 3 & 4 & 5 & \\
\hline 65 & $\begin{array}{l}\text { As ferramentas síncronas (chats, internet, telefone, etc.) disponíveis cumprem com seus } \\
\text { propósitos. }\end{array}$ & 1 & 2 & 3 & 4 & 5 & \\
\hline 66 & $\begin{array}{l}\text { As ferramentas assíncronas (e-mails, CD's, DVD's, Fax, vídeos, etc.) disponíveis cumprem } \\
\text { com seus propósitos. }\end{array}$ & 1 & 2 & 3 & 4 & 5 & \\
\hline 67 & Os ambientes de aprendizagem adotados no Curso são de fácil utilização. & 1 & 2 & 3 & 4 & 5 & \\
\hline
\end{tabular}

\section{ESPAÇO ABERTO PARA SUGESTÕES}

